\title{
Regular football training down-regulates miR-1303 muscle expression in veterans
}

\author{
A. Mancini ${ }^{1,2} \cdot$ D. Vitucci ${ }^{1} \cdot$ F. M. Orlandella ${ }^{3}$ A. Terracciano ${ }^{1,2} \cdot$ R. M. Mariniello ${ }^{1,2} \cdot$ E. Imperlini ${ }^{3} \cdot$ E. Grazioli $^{4}$.

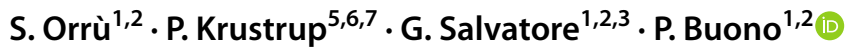

Received: 22 December 2020 / Accepted: 3 June 2021 / Published online: 1 July 2021

(c) The Author(s) 2021

\begin{abstract}
Purpose Regular exercise affects the expression of several genes, proteins and microRNAs (miRNAs) in time- and intensity-dependent manner promoting longevity. We previously identified from GeneChip Array analysis several differentially expressed genes and miRNAs in muscle from veteran football players (VPG) compared to active untrained elderly subjects (CG); here we focussed on miRNA-1303 (miR-1303). The aims of the present research were: to analyse the effects of football training on the expression of miR-1303 and to identify its putative target involved in the longevity pathways in skeletal muscle from VPG compared to CG.

Methods RNA samples from 12 VPG and 12 CG muscle biopsies were used to validate miR-1303 expression. Crossing four different bioinformatic algorithms, we identified 16 putative targets of miR-1303; from these, BAG-2, KLHL7 and KBTBD6 were chosen for further validation by Western blot analysis in LHCN-M2 human myoblasts transiently transfected with miR-1303.

Results Football training down-regulates miR-1303 expression in muscle from VPG compared to CG and the expression of BAG-2, a chaperon protein involved in the autophagy pathway, inversely correlated to overexpression of miR-1303 in a time-dependent manner, indicating that it is a miR-1303 potential target.

Conclusions This is the first report, to our knowledge, describing miR-1303 regulation in skeletal muscle by football training and the identification of a target protein, BAG-2, involved in the autophagy pathway. This result contributes to the enlargement of knowledge on the molecular mechanisms linking football training, autophagy and longevity.
\end{abstract}

Keywords Football training $\cdot$ miR-1303 $\cdot$ Autophagy $\cdot$ Longevity $\cdot$ BAG-2

Communicated by Philip D. Chilibeck.

P. Buono

buono@uniparthenope.it

1 Department of Movement Sciences and Wellness, University Parthenope, Naples, Italy

2 CEINGE-Biotecnologie Avanzate, Naples, Italy

3 IRCCS SDN, Naples, Italy

4 University "Foro Italico", Rome, Italy

5 Department of Sports Science and Clinical Biomechanics, University of Southern Denmark, Odense, Denmark

6 Sport and Health Sciences, College of Life and Environmental Sciences, St. Luke's Campus, University of Exeter, Exeter, UK

7 Danish Institute for Advanced Study (DIAS), University of Southern Denmark, Odense, Denmark

\section{Introduction}

Successful ageing is a multi-domain concept which comprises different biopsychosocial factors that can counteract the progressive decline of biological functions. Although the biological ageing process is unstoppable, it has now been established that regular exercise can counter some of the adverse physiological and cognitive consequences of ageing. In recent years, it has been reported that different genes, proteins and microRNAs (miRNAs) are involved in gene expression regulation during skeletal muscle ageing (Schmidt et al. 2019; Fochi et al. 2020).

MiRNAs are a family of single-stranded, non-coding, short RNA molecules which play a role in cellular metabolism and processes and are emerging as key regulators in gene expression at the post-transcriptional level. We previously performed a GeneChip array analysis to identify 
differentially expressed genes and miRNAs in skeletal muscles from veteran football players (VPG) compared to active untrained elderly (CG) subjects and we demonstrate that the expression of key messengers involved in the proteasome promotion and autophagy processes are up-regulated in VPG muscle (Mancini et al. 2019). Here, we further analysed Gene chip data, focussing our attention on the miR-1303 MiR-1303 is involved in the tumorigenesis and progression of several cancers as prostate cancer (Bo et al. 2019), neuroblastoma (Li et al. 2016), gastric (Zhang et al.2014) and colorectal cancer (El-Murr et al. 2012). Moreover, miR-1303 results up-regulated in patients with type 2 diabetes mellitus (T2DM), and is indicated as a novel biomarker for this pathology (Wang et al. 2016). To date, there are no evidence on miR-1303 and on the effects mediated by exercise training on the expression in skeletal muscle.

Furthermore, some miRNAs, together with heat-shock proteins (HSPs), play an important role in autophagy-associated pathways (Talebian et al. 2020). HSPs are molecular chaperones and have been implicated in longevity and ageing in many species. The autophagy pathway, being a highly regulated process for recycling intracellular protein and organelles, results in up-regulation in response to danger and differentiation signals (Au et al. 2016; Levine 2005; Shintani and Klionsky 2004). Exercise induces the activation of HSPs in skeletal muscle cells (Koh and Escobedo 2004; Paulsen et al. 2009). It has also been demonstrated that not only acute exercise but also long-term recreational training can lead to an increase in HSPs in veteran skeletal muscle (Mancini et al. 2019), together with systemic improvement: anti-oxidative potential, metabolic adaptations and cardiovascular capacity (Alfieri et al. 2015; Andersen et al. 2016; Bangsbo et al. 2015; Krustrup et al. 2010a, b; Krustrup and Krustrup 2018; Mancini et al. 2017; Schmidt et al. 2015).

Within this frame, the aims of the present study were: (a) to analyse the effects of football training on the expression of miR-1303 (b) to identify its putative targets and the possible involvement in the longevity pathways in skeletal muscle from veteran football players (VPG) compared to active untrained elderly subjects (CG).

\section{Materials and methods}

\section{Enrolment}

The samples used for this study are from participants recruited in the ClinicalTrials.gov identifier: NCT01530035. Twenty-four healthy males aged 66-72 years voluntarily participated in the study. 12 VPG and 12 CG matched for age were enrolled. VPG subjects were recruited from local football clubs in the Copenhagen area. The anthropometric and clinical characteristics of the subject participating in the study are reported in Table 1. In detail, VPG had an average age, height and weight, BMI and fat percentage of $69 \pm 3$ years, $177 \pm 3 \mathrm{~cm}, 78 \pm 7 \mathrm{~kg}, 24.8 \pm 2.1$ and $22.3 \pm 1.5 \%$, respectively, and a maximal oxygen uptake of $35 \pm 5 \mathrm{ml} / \mathrm{min} / \mathrm{kg}$. On average, they had been active football players for $49 \pm 10$ years (range: $25-58$ years), and for the last 10 years they had attended one football training session per week $(1.5 \pm 0.6 \mathrm{~h} / \mathrm{session})$ and played $26 \pm 12$ football matches per year $(5 \mathrm{v} 5$ or $11 \mathrm{v} 11)$. Two of the 12 footballers in VPG were former elite football players, whereas the remaining 10 were life-long recreational football players. The control group participants were healthy habitually active individuals recruited via ads in local newspapers, with an average age, height, weight, BMI and fat percentage of $68 \pm 2$ years, $176 \pm 4 \mathrm{~cm}, 83 \pm 10 \mathrm{~kg}, 26.9 \pm 3.4$, $28.8 \pm 1.4 \%$, respectively, and a maximal oxygen uptake of $28 \pm 4 \mathrm{ml} / \mathrm{min} / \mathrm{kg}$. CG were on average active $2 \mathrm{~h} /$ week on average (range $0-9 \mathrm{~h} /$ week), mainly with everyday activities such as walking, housing and gardening. The participants in CG had not been involved in regular structured exercise training for a major part of their adult life (Schmidt et al. 2015). Exclusion factors were a history or symptoms of cardiovascular disease or cancer, type 2 diabetes, hypertension, nephropathy or musculoskeletal complaints. The study was conducted in line with the Declaration of Helsinki and was approved by the local research ethics committee in Copenhagen, H-1-2011-013. The subjects' habitual fitness level was assessed by a questionnaire. All participants signed an informed consent form.

\section{Muscle biopsies}

Muscle biopsies were obtained under standardised conditions between 7 and 10 a.m. after an overnight fast, and taken from the vastus lateralis under local anaesthetic (1\% Lidocaine, Amgros 742122, Copenhagen, Denmark) using the

Table 1 Anthropometric and clinical characteristics of subjects participating to the study

\begin{tabular}{lll}
\hline & VPG & CG \\
\hline Number of subjects & 12 & 12 \\
Age $(\mathrm{yrs})$ & $69 \pm 3$ & $68 \pm 2$ \\
Height $(\mathrm{cm})$ & $177 \pm 3$ & $176 \pm 4$ \\
Body weight $(\mathrm{kg})$ & $78 \pm 7$ & $83 \pm 10^{*}$ \\
BMI $\left(\mathrm{kg} / \mathrm{m}^{2}\right)$ & $24.8 \pm 2.1$ & $26.9 \pm 3.4^{*}$ \\
Total body fat $(\%)$ & $22.3 \pm 1.5$ & $28.8 \pm 1.4^{*}$ \\
VO $_{2}$ peak $(\mathrm{ml} / \mathrm{kg} / \mathrm{min})$ & $35 \pm 5$ & $28 \pm 4^{*}$ \\
\hline
\end{tabular}

Value are reported as means $\pm \mathrm{SD}$

$* p<0.05$ VPG vs CG 
Bergstrom technique as detailed in Andersen et al. (2016). Briefly, the muscle sample (40 mg wet weight) was immediately frozen in liquid nitrogen and stored at $-80{ }^{\circ} \mathrm{C}$ pending further analysis. All participants abstained from intense physical activity or training for $48-72 \mathrm{~h}$ before the biopsies.

\section{MiRNA expression profiles in muscle biopsies}

Sample RNA extraction was performed as previously described (Mancini et al. 2017). Briefly, total RNA was extracted from the muscle biopsies using a miRNeasy Mini kit (Qiagen, Hilden, Germany) according to the manufacturer's instructions. The RNA integrity number (RIN) of samples was assessed using a Bio-Rad Experion automated electrophoresis station (Hercules, CA, United States) before cDNA synthesis. 12 RNA samples of VPG and 7 RNA samples $C G$ passed the criterion of RIN> 7. 6 RNA samples from VPG and 6 RNA from CG were used to obtain three pooled VPG (named VPG1, VPG2, and VPG3) and three pooled CGs (named CG1, CG2, and CG3) libraries that underwent to microarray assay to determine gene expression profile, as previously described (Mancini et al 2019). We carried out the profiling using GeneChip R Human Transcriptome Array 2.0 (HTA 2.0, Affymetrix, Santa Clara, CA, United States). The RNA samples were prepared using the WT PLUS Reagent kit, followed by hybridization on HTA 2.0 microarray chips. $100 \mathrm{ng}$ of total RNA were subjected to two cycles of cDNA synthesis with the Affymetrix WT PLUS expression Kit. DNA fragments are then terminally labelled by terminal deoxynucleotidyl transferase (Affymetrix) with biotin. The biotinylated DNA was hybridised to the Human Genechip. HTA 2.0 Arrays (Affymetrix), containing more than 285.000 full-length transcripts covering 44.700 coding genes and 22.800 non-coding genes selected from H. sapiens genome databases RefSeq, ENSEMBL, and GenBank. The data obtained from the GeneChip were deposited in the Gene Expression Omnibus of the NCBI (Edgar et al. 2002) and are accessible through GEO Series Accession Number GSE125830-(Mancini et al. 2019). The validation of miR-1303 was performed on individual samples (12 VPG and $7 \mathrm{CG}$ ) by RT $q$ PCR (see below).

\section{Bioinformatic analysis}

Computational predictions of the putative targets of miR1303 were performed using public target-prediction tools with different algorithms: TargetScan 7.0, http://www.targe tscan.org; miRDB, http://mirdb.org; microRNA, http://www. microrna.org; MicroT4, http://diana.imis.athena-innovation. gr/DianaTools. As for TargetScan 7.0, we filtered the 4445 putative targets of miR-1303 by setting the TargetScan CS (context score) $\leq-0.4$. Similarly, amongst 448 putative targets obtained from miRDB, a minimum cutoff value of 56 was selected for the target SCORE. No filter was applied to screen the list of putative targets obtained by microRNA and MicroT4 tools.

\section{Cell culture and transient transfection in LHCN-M2}

The human skeletal muscle LHCN-M2 cell line, kindly provided by Dr Vincent Mouly (Institut de Myologie, Paris, France) (Zhu et al. 2007), was maintained at a subconfluent density $(70 \%)$ at $37{ }^{\circ} \mathrm{C}$ in $5 \% \mathrm{CO}_{2}$ in growth medium (GM) as described in Vitucci et al. (2018). Cells were seeded between 60 and $80 \%$ confluence in 6-well Petri dishes and cell transfection was performed using according to the manufacturer's instructions (Thermo Fisher Scientific, Inc., Italy). $5 \mu \mathrm{l}$ of Lipofectamine ${ }^{\mathrm{TM}}$ RNAiMAX Transfection Reagent (Thermo Fisher Scientific, Inc., Italy) was diluted in $250 \mu \mathrm{l}$ of Opti-MEM medium and $5 \mu 1$ mirVana ${ }^{\circledR}$ miRNA mimic miR-1303 (ID\#: MC13799;GGCUGGGCAACA UAGCGAGACCUCAACUCUACAAUUUUUUUUUUU UUAAAUUUUAGAGACGGGGUCUUGCUCUGUUGC CAGGCUUU) or mirVana ${ }^{\mathrm{TM}}$ miRNA Mimic, Negative Control \#1 (ID\#: 4464058, named miR-CTRL) synthesised by Thermo Fisher Scientific in $250 \mu$ of Opti-MEM ${ }^{\circledR}$ Medium. Subsequently the miR-1303 or miR-CRTL was diluted with Lipofectamine ${ }^{\circledR}$ RNAiMAX Reagent (1:1 ratio) and incubated for $5 \mathrm{~min}$ at RT. SiRNA-lipid complex was added to cells which were then incubated for 24 and $48 \mathrm{~h}$ at $37^{\circ} \mathrm{C}$ in $5 \% \mathrm{CO}_{2}$.

\section{RNA extraction and quantitative real-time-PCR (RTqPCR)}

Total RNA was extracted from the 19 muscle biopsies $(N=12$ VPG and $N=7 \mathrm{CG}$ ) and from LHCN-M2 cell lines 24 and $48 \mathrm{~h}$ after transfection (n.3 independent experiments for each time point were performed) and integrity assessed as described above. $10 \mathrm{ng}$ of total RNA obtained from individual VPG (n.12) and CG (n.7) muscle biopsies and from the LHCNM2, were reverted in cDNA using a TaqMan microRNA reverse transcription kit (Thermo Fisher Scientific, Inc., Italy) with specific reverse primer and with the following thermal cycles: $16{ }^{\circ} \mathrm{C}$ and $42{ }^{\circ} \mathrm{C}$ for $30 \mathrm{~min}$ each, followed by $85^{\circ} \mathrm{C}$ for $5 \mathrm{~min}$ according to the manufacturer's instructions. Subsequently, the mature form of miRNAs was detected using the miR-1303 primers (ID 002792) and TaqMan Universal Master Mix II purchased from Thermo Fisher Scientific. RNU44 (ID 001094) expression level was used as internal control for the normalisation of miR-1303. For each cDNA, the RT $q \mathrm{PCR}$ 
reaction was performed in triplicate with the following thermal cycling parameters: $95^{\circ} \mathrm{C}$ for $10 \mathrm{~min}$, followed by 40 cycles of $95^{\circ} \mathrm{C}$ for $15 \mathrm{~s}$ and $60^{\circ} \mathrm{C}$ for $1 \mathrm{~min}$. RNU44 expression level was used as internal control for the normalisation of miR-1303 and the fold changes were calculated using the formula $2^{-\Delta \Delta \mathrm{Ct}}$ (Livak et al. 2001).

\section{Western blotting}

Twenty-four muscle biopsies (12 VPG and 12 CG) were mechanically pulverised and protein extraction was performed as previously described (Mancini et al. 2017). Briefly, protein samples $(50 \mu \mathrm{g}$ each) were separated on 4-20\% precast gradient polyacrylamide gels (Bio-Rad), transferred to the Hybond ECL nitrocellulose membrane (GE Healthcare, Italy) and checked by Ponceau S staining to verify equal loading. The membranes were immunoblotted using mouse monoclonal antibodies against BAG cochaperone 2 (BAG-2), glyceraldehyde- 3-phosphate dehydrogenase (GAPDH) (1:1000; Santa-Cruz Biotechnology Inc, USA.) and rabbit polyclonal antibodies against kelch repeat and BTB domain containing 6 (KBTBD6) and kelch-like family member 7 (KLHL7) (Abcam, 1:1000). Blots were incubated with appropriate horseradish peroxidase-conjugated secondary antibody and target proteins were visualised by ECL detection (GE Healthcare, Italy). Densitometric measurements were carried out using Quantity One software (Bio-Rad, Italy) as reported elsewhere (Imperlini et al. 2015). GAPDH protein was used to estimate the total amount of loaded proteins. Results were normalised as a percentage of the mean of controls in each membrane.

\section{Statistical analysis}

Group comparisons were examined by means of ANOVA statistical model. Relative miRNA expression was reported as relative quantization (RQ) values, calculated as $2^{-\Delta \Delta C t}$, where $\Delta \mathrm{Ct}$ is calculated as $\mathrm{Ct}$ target gene- $\mathrm{Ct}$ housekeeping genes (RNU44 mRNA expression). One-way ANOVA was used to analyse miR-1303 expression in muscle from CG and VPG; relative protein abundance of BAG-2, KBTBD6 and KLHL7, was calculated respect to GAPDH abundance. Differences between VPG vs CG were considered statistically significant at $p<0.05$. Two-way mixed ANOVA [within-subjects factor: time ( $24 \mathrm{~h}$ and $48 \mathrm{~h}$ ); between-subjects factor: miR-treat (miR-1303 and miR-CTRL)] was performed; in the presence of positive miR-treat $\times$ time interaction, Bonferroni post hoc test was carried out. Statistical analysis was performed with StatView software (version 5.0.1.0; SAS Institute Inc., Cary, NC, United States).

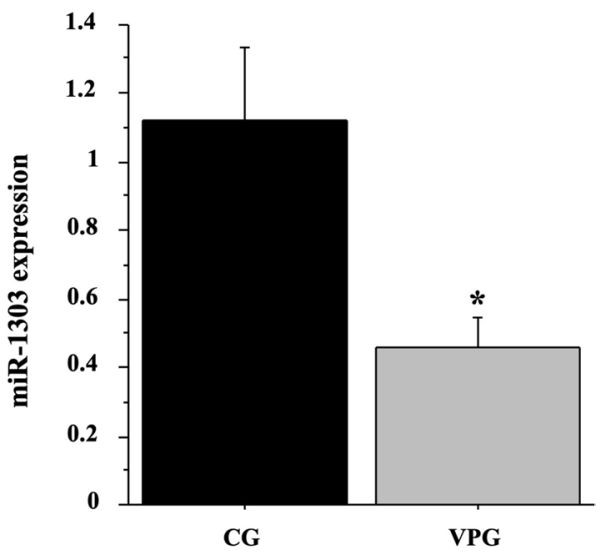

Fig. 1 miR-1303 expression in muscle from VPG compared to CG using $\mathrm{RT} q \mathrm{PCR}$ analysis. Quantitative analysis expression of miR1303 was determined in skeletal muscle biopsies from 7 CG (black bar) and 12 VPG subjects (grey bar). Data represent the mean ( \pm SD) of miR-1303 relative expression in VPG and CG muscle biopsies $\left(2^{-}\right.$ $\Delta \Delta \mathrm{CT}$ ) and compared by one-way ANOVA; differences were considered significant at $* p<0.05$ vs $\mathrm{CG}$

\section{Results}

\section{Identification of differently expressed miRNA in skeletal muscle from VPG and CG}

We previously identified the differently expressed genes (DEGs) and miRNAs in skeletal muscle from VPG compared to CG subjects by means of a GeneChip analysis and deposited them in NCBI's Gene Expression Omnibus (GEO Series Accession Number GSE125830 -Mancini et al. 2019). In particular, we previously demonstrated that messengers associated with autolysosome and the proteasome-mediated pathways were significantly up-regulated in skeletal muscle by VPG compared to CG. Here we focussed on differentially expressed miRNAs in skeletal muscle by VPG versus CG subjects and on their putative interactors. The GeneChip analysis showed that 12 miRNAs were differentially expressed in muscle VPG respect to CG; amongst them, we focussed our attention on miR-1303 $(p<0.01)$. We confirmed the different expression of miRNA- 1303 in the 12 individual VPG compared to 7 CG muscle samples by RTqPCR ( $p<0.05$, Fig. 1).

\section{Identification of putative miR-1303 targets through bioinformatic algorithms}

The targets of miR-1303 were analysed using public targetprediction tools with different algorithms. In particular, we 


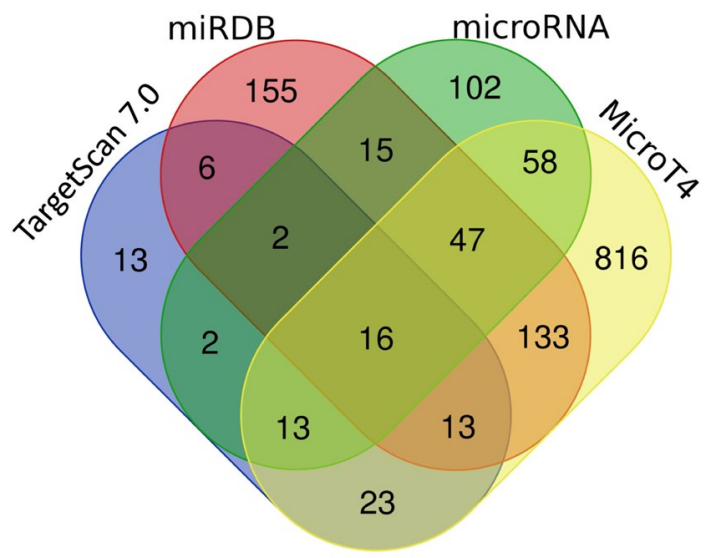

Fig. 2 Venn diagram of miR-1303 putative targets. Venn diagram shows overlapping miR-1303 targets specific for each bioinformatic tool: TargetScan 7.0, miRDB, microRNA and MicroT4

Table 2 miR-1303 putative targets predicted by crossing of four different algorithms: (TargetScan, miRDB, microRNA and MicroT4)

\begin{tabular}{ll}
\hline Gene symbol & Protein name \\
\hline PDIA3 & Protein disulfide isomerase family A, member 3 \\
MLF1 & Myeloid leukaemia factor 1 \\
KBTBD6 & Kelch repeat and BTB (POZ) domain containing 6 \\
KLHL7 & Kelch-like family member 7 \\
YWHAZ & Tyrosine 3-monooxygenase/tryptophan 5-monooxyge- \\
& nase activation protein, zeta polypeptide \\
TNFAIP8L3 & Tumour necrosis factor, alpha-induced protein 8-like 3 \\
TMEM40 & Transmembrane protein 40 \\
STATH & Zinc finger and BTB domain containing 6 \\
P2RY14 & Purinergic receptor P2Y, G-protein coupled, 14 \\
EIF1B & Eukaryotic translation initiation factor 1B \\
TG & Thyroglobulin \\
BAG-2 & BCL2-associated athanogene 2 \\
VAMP3 & Vesicle-associated membrane protein 3 \\
SLC35E3 & Solute carrier family 35, member E3 \\
AGBL2 & ATP/GTP binding protein-like 2 \\
PAPOLB & Poly(A) polymerase beta (testis specific) \\
\hline
\end{tabular}

focussed on the top putative targets identified by TargetScan7.0 (88), miRDB (386), microRNA (255) and MicroT4 (1119), respectively, using cutoff and significance threshold as indicated in "Materials and methods". Successively, we overlapped the outputs of the four different tools to optimise the in silico target prediction (Fig. 2), thus identifying 16 putative targets of miR-1303 (Table 2).

Amongst predicted target genes, BAG-2, KLHL7 and KBTBD6, involved in the protein quality control proteasome pathway, were chosen for further validation. Interestingly, BAG-2, a chaperon protein involved in preventing disregulated ubiquitination of misfolded protein by CHIP (carboxyl terminus of Hsp70-interacting protein), resulted up-regulated $(p<0.05)$ in skeletal muscle from VPG compared to CG (Fig. 3A, B).

\section{BAG-2 is the target of miR-1303 in LHCN-M2}

To investigate the effect of miR-1303 on BAG-2 protein expression, we overexpressed miR-1303 in human myoblast cell line LHCN-M2; as a negative control miR-CTRL was used. The transfection efficiency was verified by $\mathrm{RT} q \mathrm{PCR}$ after 24 and $48 \mathrm{~h}$ (miR-treat effect: $p<0.001$, Fig. 4A). Twoway mixed ANOVA [within-subjects factor: time $(24 \mathrm{~h}$ and $48 \mathrm{~h}$ ); between-subjects factor: miR-treat (miR-1303 and miR-CTRL)] was performed (miR-treat $\times$ time interaction: $p<0.01$ ) Bonferroni post hoc test was carried out (Fig. 4B, C). One-way ANOVA showed a significant increase of miR-1303 expression at $24 \mathrm{~h}(p<0.01)$; the expression was reduced at $48 \mathrm{~h}$ albeit higher than miR-CTRL $(p<0.05)$.

\section{Discussion}

The main objectives of this study were to assess the effects of football training on skeletal muscle miR-1303 expression level and to find its putative interactors. We demonstrate that miR-1303 expression was down-regulated in muscle from VPG compared to active untrained elderly subjects and we identify BAG-2, a chaperon protein involved in preventing unregulated ubiquitination of misfolded protein by CHIP, as a down-regulated molecule by miR-1303 in human myoblast LHCN-M2 cells. To the best of authors' knowledge, this is the first report describing miR-1303 regulation by football training and the identification of the putative target protein.

MiRNAs regulate different cellular processes including proliferation, motility and apoptosis (Bartel 2004). MiRNAs with preferred expression in skeletal muscle are termed "MyomiRs" and regulate muscle development, plasticity and functionality (Güller and Russell 2010; Moresi et al. 2015). Regular exercise promotes positive adaptations in skeletal muscle. In particular, it improves muscle mass, resistance to fatigue and cardiovascular fitness, increasing general quality of life (Petriz et al. 2017; Naseeb et al. 2017; Gries et al. 2018). Several studies have investigated the effects of different types of exercise on miRNA expression (Da Silva et al. 2020; Falzone et al. 2020; Fochi et al. 2020). Only a few studies have investigated the correlation between exercise and miRNA expression in the elderly, particularly in acute or short-term training. A recent meta-analysis evidenced only nine circulating miRNAs differently expressed in young compared to elderly subjects after acute exercise (Margolis et al. 2017; Gopinath et al. 2018).

Regular exercise training mediates the reduction in the risk of chronic non-communicable diseases (NMCT), 


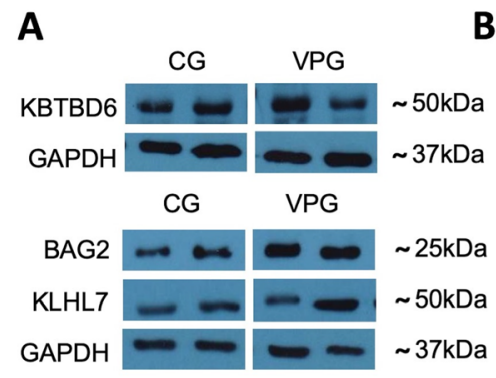

B
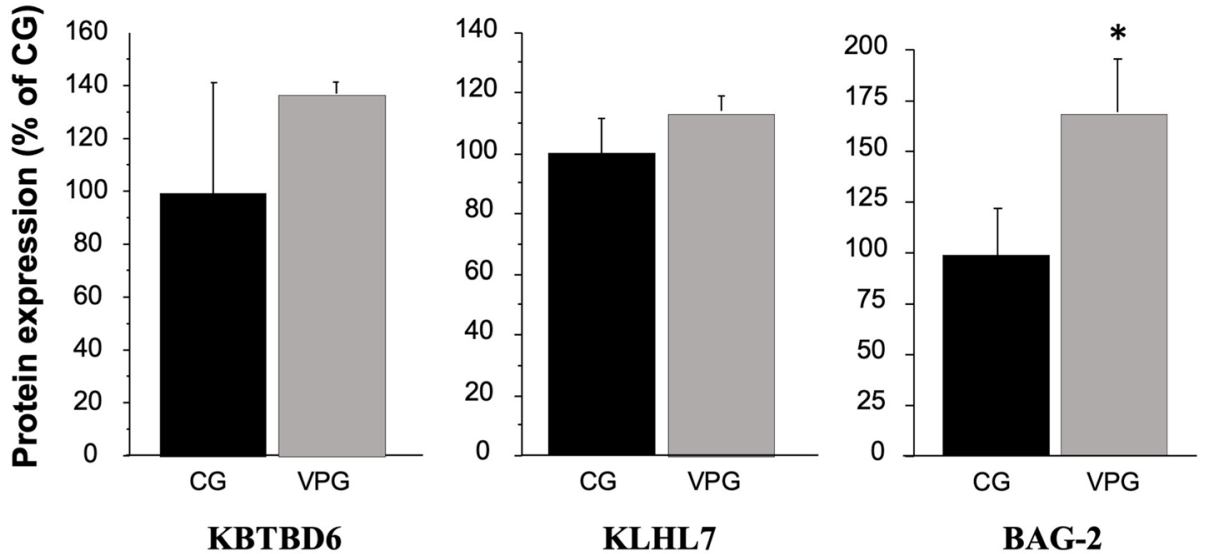

Fig. 3 KBTBD6, KLHL7 and BAG-2 protein expression levels in skeletal muscle from CG and VPG. Protein expression levels of KBTBD6, KLHL7 and BAG-2 predicted targets of miR-1303 evaluated by Western Blotting in muscle biopsies from 12 CG (black bars) and 12 VPG (grey bars) and analysed by one-way ANOVA. A Rep-

including cancer (Cartee et al. 2016; Gebel et al. 2015; Kyu et al. 2016) and promotes wellbeing and longevity (Garatachea et al. 2015), also through the regulation of miRNAs and protein expression. In the last few years, adapted sport training, particularly football, has been reported as holistic positive paradigm, linking training to improved cardiovascular, metabolic and musculoskeletal fitness, also in the elderly (Krustrup et al 2010a, 2018; Bangsbo et al. 2015; Andersen et al. 2016; Krustrup and Krustrup 2018; Imperlini et al. 2020). Regular training promotes successful ageing, activating the autophagy process in muscle tissue (Fan et al. 2016). Despite growing evidence linking regular exercise to longevity, the underlying molecular mechanisms are not completely understood. In particular, the effects mediated by football training on miRNA muscle expression associated with longevity, to our knowledge, have not been reported until now. In this context, we provide evidence that miR1303 expression was down-regulated in skeletal muscle from VPG compared to active untrained elderly subjects. MiR1303 also plays an important role in cancer development by acting as an oncogene in different types of tumours, such as in neuroblastoma where it promotes proliferation $(\mathrm{Li}$ et al. 2016) and in gastric cancer to modulate proliferation and invasion (Zhang et al. 2014), in colorectal cancer (El-Murr et al. 2012) and in prostate cancer progression and development (Liu et al. 2019). In addition, miR-1303 overexpression was associated with microvascular complications in T2DM patients (Wang et al. 2016).

We recently demonstrated that in veteran muscle, the autophagy pathways were enhanced: we found up-expression of Beclin (Bcl-2), ATG (ATG5-ATG12 complex), resentative blots are reported for each protein; $\mathbf{B}$ data represent the optical densitometry means $( \pm S D)$ of three different experiments reported as a percentage of $\mathrm{CG}$ expression; differences were considered significant at $* p<0.05$ vs $C G$

heat-shock (HSC70/90) and PSMD13 (proteasome complex) proteins, suggesting a more efficient protein quality control process in veteran trained muscle compared to untrained active elderly subjects, which correlates with longevity (Quan and Lee 2013; Walczak et al. 2013; Wedel et al. 2018; Mancini et al. 2019). The maintenance of proteostasis is fundamental for the function and viability of cells. On the other hand, the deterioration of these pathways is associated with several diseases such as Alzheimer's, Parkinson's and T2DM; moreover, proteostasis pathway impairment is a hallmark of ageing (Harlt et al. 2011; He and Klionsky 2009; Ross and Poirier 2004). Molecular chaperon proteins, like HSPs, are involved in correct protein-folding and in the autophagic lysosomal pathway (Douglas and Dillin 2010; Lopez-Otin et al. 2013). BAG-2 belongs to a family of 6 BCL2-associated athanogene members (BAGs) (Behl 2016) which are conserved in different non-human, mammal and plant species, suggesting a key biological role in cell physiology (Doukhanina et al. 2006; Takayama and Reed 2001). BAG-2 improves correct protein folding by interacting with HSP70/CHIP complex and prevents aggregations of misfolded proteins (Arndt et al. 2005; Dai et al. 2005; Schönbühler et al. 2016; Wang et al. 2008); furthermore, BAG proteins can bind to various transcriptional factors, to regulate various processes such as cell apoptosis and differentiation (Qin et al. 2016).

Our results indicate that BAG-2 protein is up-regulated in muscle from veterans compared to active untrained elderly subjects, and it is in turn associated with a healthier profile although, up to now, no direct evidence correlating 


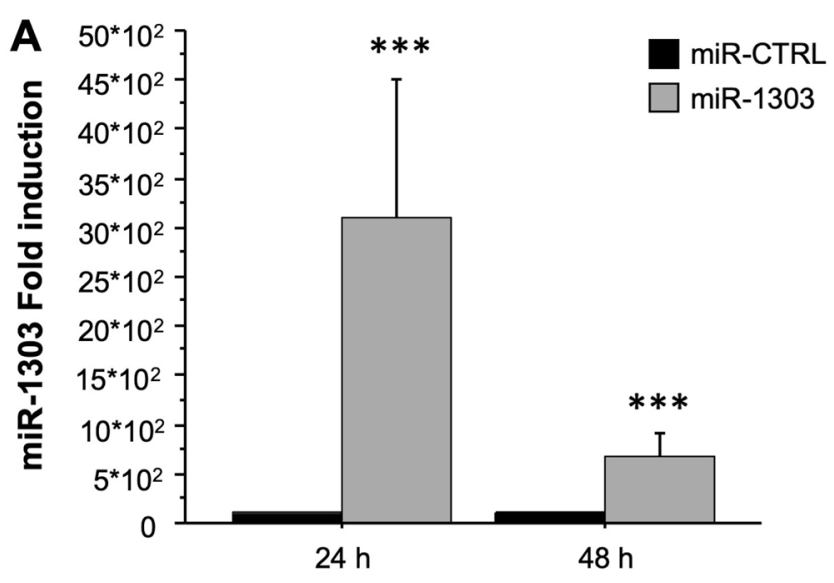

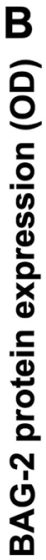

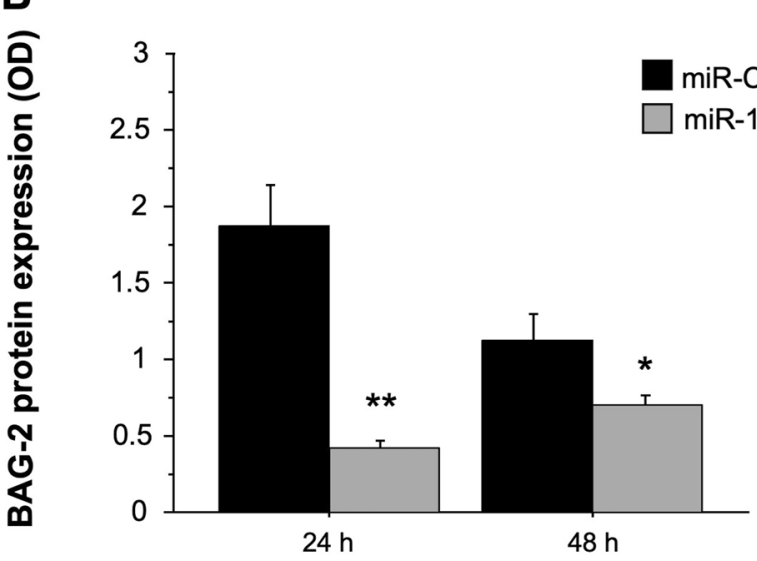

C

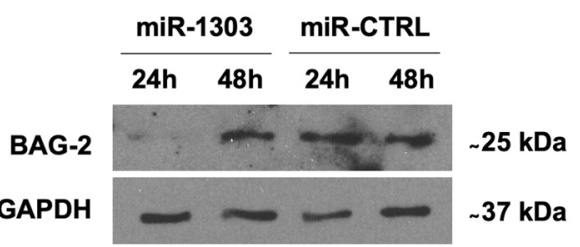

Fig. 4 BAG-2 is the target of miR-1303 in LHCN-M2. A Quantitative analysis expression of miR-1303 was determined in LHCN-M2 cells. Fold-induction represents miR-1303 compared to miR-CTRL expression after 24 and $48 \mathrm{~h}$ of transient transfection. An arbitrary value of 1 was assigned to the expression of miR-CTRL. one-way ANOVA showed significant differences $* * * p<0.001$ for miR-1303 (grey bars) compared to miR-CTRL (black bars) at 24 and $48 \mathrm{~h}$. B Protein

miR-1303 expression and longevity pathways is known. It is worth noting that BAG-2 up-expression in muscle from VPG subjects is in line with the increase of Bcl-2, ATG5ATG12 complex, HSC70/90 and PSMD13 protein expression involved in the lysosomal and proteasome pathways as we previously reported (Mancini et al. 2019). Therefore, we can speculate that football training positively is related to a healthier profile and longevity promotion in veterans.

In conclusion, we provide evidence, for the first time, that miR-1303 expression and BAG-2 protein, its putative target, are regulated by football training in veterans muscle tissue. We also contribute to enhance the knowledge of molecular mechanisms linking 1 football training to longevity. The limited number of subjects investigated represents the main limitation of this study, as well as the absence of females. Further elucidation of the effects mediated by different types expression levels of BAG-2, the target of miR-1303, were analysed by Western Blotting in LHCN-M2 transfected with miR-1303. Data represent the optical densitometry means $( \pm S D)$ of three different experiments. Differences were considered significant at $* * p<0.01$ for miR-1303 (grey bars) compared to miR-CTRL (black bars) transfected cells at $24 \mathrm{~h}$ and at $48 \mathrm{~h} * p<0.05$. C Representative blots are reported for each protein analysed

of sports training on muscle miR-1303 and BAG-2 protein expression will contribute to greater understanding of this process in females too. In the same way, it will be useful to investigate these processes on subjects who have been playing football and/or other types of sports for a shorter time and to discriminate whether these effects are due to the lifelong football training or only to football training.

Finally, research into circulating miR-1303 represents a future goal to define healthy ageing biomarkers.

Author contributions $\mathrm{AM}$ and $\mathrm{PB}$ conceived the manuscript, and made contributions on acquisition, analysis, and interpretation of data. DV, FMO, AT, RMM and EG carried out the experiments and performed statistical analysis of data. PK enrolled the subjects and collected the muscle samples. EI and SO performed bioinformatic analysis. PB, GS, $\mathrm{PK}$ and SO revised the manuscript. 
Funding Open access funding provided by Università Parthenope di Napoli within the CRUI-CARE Agreement. This study was funded by the grant "Bando di Ateneo per il sostegno alla partecipazione ai bandi di ricerca competitiva per l'anno 2016 (quota C)"; "Bando di Ateneo per il sostegno alla partecipazione ai bandi di ricerca individuale (quota A) per l'anno 2017" (code DSMB187) from the University of Naples "Parthenope" and Bando PRIN 2017_Prot.2017RS5M44.

\section{Declarations}

Conflict of interest The authors declare no conflict of interest.

Open Access This article is licensed under a Creative Commons Attribution 4.0 International License, which permits use, sharing, adaptation, distribution and reproduction in any medium or format, as long as you give appropriate credit to the original author(s) and the source, provide a link to the Creative Commons licence, and indicate if changes were made. The images or other third party material in this article are included in the article's Creative Commons licence, unless indicated otherwise in a credit line to the material. If material is not included in the article's Creative Commons licence and your intended use is not permitted by statutory regulation or exceeds the permitted use, you will need to obtain permission directly from the copyright holder. To view a copy of this licence, visit http://creativecommons.org/licenses/by/4.0/.

\section{References}

Alfieri A, Martone D, Randers MB, Labruna G, Mancini A, Nielsen JJ, Bangsbo J, Krustrup P, Buono P (2015) Effects of long-term football training on the expression profile of genes involved in muscle oxidative metabolism. Mol Cell Probes 29:43-47

Andersen TR, Schmidt JF, Pedersen MT, Krustrup P, Bangsbo J (2016) The effects of 52 weeks of soccer or resistance training on body composition and muscle function inC65-year-old healthy males-a randomized controlled trial. PLoS ONE 11:e0148236. https://doi. org/10.1371/journal.pone.0148236

Arndt V, Daniel C, Nastainczyk W, Alberti S, Höhfeld J (2005) BAG-2 acts as an inhibitor of the chaperone-associated ubiquitin ligase CHIP. Mol Biol Cell 16(12):5891-5900. https://doi.org/10.1091/ mbc.e05-07-0660

Au KY, Pong JCH, Ling WL, Li JCB (2016) MiR-1303 regulates mycobacteria induced autophagy by targeting Atg2B. PLoS ONE. https://doi.org/10.1371/journal.pone.0146770

Bangsbo J, Hansen PR, Dvorak J, Krustrup P (2015) Recreational football for disease prevention and treatment in untrained men: a narrative review examining cardiovascular health, lipid profile, body composition, muscle strength and functional capacity. Br J Sports Med 49:568-576. https://doi.org/10.1136/bjsports-2015-094781

Bartel DP (2004) MicroRNAs: genomics, biogenesis, mechanism, and function. Review Cell 116:281-297

Behl C (2016) Breaking BAG: the Co-chaperone BAG3 in health and disease. Trends Pharmacol Sci 37(8):672-688. https://doi.org/10. 1016/j.tips.2016.04.007

Bo L, Wiedong Z, Huiyang J et al (2019) MiR-1303 promotes the proliferation, migration and invasion of prostate cancer cells through regulating the $\mathrm{Wnt} / \beta$-catenin pathway by targeting DKK3. Exp Ther Med 18:4747-4757

Cartee GD, Hepple RT, Bamman MM, Zierath JR (2016) Exercise promotes healthy aging of skeletal muscle. Cell Metab 23(6):1034 1047. https://doi.org/10.1016/j.cmet.2016.05.007

Da Silva FC, da Rosa IR, Andrade A, Costa VP, Filho PJBG, da Silva R (2020) Effects of physical exercise on the expression of MicroRNAs: a systematic review. J Strength Cond Res 34:270-280
Dai Q, Quian SB, Li HH, McDonough H, Borchers C et al (2005) Regulation of the cytoplasmic quality control protein degradation pathway by BAG2. J Biol Chem 280:38673-38681

Douglas PM, Dillin A (2010) Protein homeostasis and aging in neurodegeneration. J Cell Biol 6(190):719-729

Doukhanina EV, Chen S, van der Zalm E, Godzik A, Reed J, Dickman MB (2006) Identification and functional characterization of the BAG protein family in Arabidopsis thaliana. J Biol Chem 281(27):18793-18801. https://doi.org/10.1074/jbc.M511794200

Edgar R, Domrachev M, Lash AE (2002) Gene expression omnibus: NCBIgene expression and hybridization array data repository. Nucleic Acids Res. 30:207-210. https://doi.org/10.1093/nar/ 30.1.207

El-Murr N, Abidi Z, Wanherdrick K, Svrcek M, Gaub MP, Fléjou JF, Hamelin R, Duval A, Lesuffleur T (2012) MiRNA genes constitute new targets for microsatellite instability in colorectal cancer. PLoS ONE 7(2):e31862. https://doi.org/10.1371/journal.pone.0031862

Falzone L, Grimaldi M, Celentano E, Augustin LSA, Libra M (2020) Identification of modulated MicroRNAs associated with breast cancer, diet, and physical activity. Cancers 12:2555

Fan J, Kou X, Jia S, Yang X, Yang Y, Chen N (2016) Autophagy as a potential target for sarcopenia. J Cell Physiol 231(7):1450-1459. https://doi.org/10.1002/jcp.25260

Fochi S, Giuriato G, De Simone T, Gomez-Lira M, Tamburin S, Del Piccolo L, Schena F, Venturelli M, Romanelli MG (2020) Regulation of microRNAs in satellite cell renewal, muscle function, sarcopenia and the role of exercise. Review Int J Mol Sci 21:6732

Garatachea N, Pareja-Galeano H, Sanchis-Gomar F, Santos-Lozano A, Fiuza-Luces C, Morán M, Emanuele E, Joyner MJ, Lucia A (2015) Exercise attenuates the major hallmarks of aging. Rejuvenation Res 18(1):57-89. https://doi.org/10.1089/rej.2014.1623

Gebel K, Ding D, Chey T, Stamatakis E, Brown WJ, Bauman AE (2015) Effect of moderate to vigorous physical activity on allcause mortality in middle-aged and older Australians. JAMA Intern Med 175(6):970-977. https://doi.org/10.1001/jamaintern med.2015.0541

Gopinath B, Kifley A, Flood VM, Mitchell P (2018) Physical activity as a determinant of successful aging over ten years. Sci Rep 8:10522

Gries KJ, Raue U, Perkins RK, Lavin KM, Overstreet BS, D’Acquisto LJ, Graham B, Finch WH, Kaminsky LA, Trappe TA, Trappe S (2018) Cardiovascular and skeletal muscle health with lifelong exercise. J Appl Physiol 125(5):1636-1645. https://doi.org/10. 1152/japplphysiol.00174.2018

Güller I (2010) Russell AP (2010) MicroRNAs in skeletal muscle: their role and regulation in development, disease and function. Review J Physiol 588:4075-4087

Hartl FU, Bracher A, Hayer-Hartl M (2011) Molecular chaperones in protein folding and proteostasis. Nature 475(7356):324-332. https://doi.org/10.1038/nature10317

He C, Klionsky DJ (2009) Regulation mechanisms and signaling pathways of autophagy. Annu Rev Genet 43:67-93. https://doi.org/10. 1146/annurev-genet-102808-114910

Imperlini E, Spaziani S, Mancini A, Caterino M, Buono P, Orrù S (2015) Synergistic effect of DHT and IGF-1 hyperstimulation in human peripheral blood lymphocytes. Proteomics 15:1813-1818. https://doi.org/10.1002/pmic.201400242

Imperlini E, Mancini A, Orrù S, Vitucci D, Di Onofrio V, Gallè F, Valerio G, Salvatore G, Liguori G, Buono P, Alfieri A (2020) Long-term recreational football training and health in aging. Int $\mathrm{J}$ Environ Res Public Health 17:2087

Koh TJ, Escobedo J (2004) Cytoskeletal disruption and small heat shock protein translocation immediately after lengthening 
contraction. AJP Cell Physiology 286(3):C713-C722. https:// doi.org/10.1152/ajpcell.00341.2003

Krustrup P, Krustrup BR (2018) Football is medicine: it is time for patients to play! Br. J Sports Med 52:1412-1414. https://doi.org/ 10.1136/bjsports-2018-099377

Krustrup P, Aagaard P, Nybo L, Petersen J, Mohr M, Bangsbo J (2010a) Recreational football as a health promoting activity: a topical review. Scand J Med Sci Sports 20(Suppl 1):1-13

Krustrup P, Christensen JF, Randers MB, Pedersen H, Sundstrup E, Jakobsen MD, Krustrup BR, Nielsen JJ, Suetta C, Nybo L, Bangsbo J (2010b) Muscle adaptations and performance enhancements of soccer training for untrained men. Eur J Appl Physiol 108:1247-1258

Krustrup P, Williams CA, Mohr M, Hansen PR, Helge EW, Elbe AM, de Sousa M, Dvorak J, Junge A, Hammami A, Holtermann A, Larsen MN, Kirkendall D, Schmidt JF, Andersen TR, Buono P, Rørth M, Parnell D, Ottesen L, Bennike S, Nielsen JJ, Mendham AE, Zar A, Uth J, Hornstrup T, Brasso K, Nybo L, Krustrup BR, Meyer T, Aagaard P, Andersen JL, Hubball H, Reddy PA, Ryom K, Lobelo F, Barene S, Helge JW, Fatouros IG, Nassis GP, Xu JC, Pettersen SA, Calbet JA, Seabra A, Rebelo AN, Figueiredo P, Póvoas S, Castagna C, Milanovic Z, Bangsbo J, Randers MB, Brito J (2018) The "Football is Medicine" platform-scientific evidence, large-scale implementation of evidence-based concepts and future perspectives. Scand J Med Sci Sports 28(Suppl 1):3-7

Kyu HH, Bachman VF, Alexander LT, Mumford JE, Afshin A, Estep K, Veerman JL, Delwiche K, Iannarone, (2016) Physical activity and risk of breast cancer, colon cancer, diabetes, ischemic heart disease, and ischemic stroke events: systematic review and doseresponse meta-analysis for the Global Burden of Disease Study 2013. BMJ 354:i3857. https://doi.org/10.1136/bmj.i3857

Levine B (2005) Eating oneself and uninvited guests: autophagyrelated pathways in cellular defense. Cell 120(2):159-162. https:// doi.org/10.1016/j.cell.2005.01.005 (PMID: 15680321)

Li Z, Xu Z, Xie Q, Gao W, Xie J, Zhou L (2016) miR-1303 promotes the proliferation of neuroblastoma cell SH-SY5Y by targeting GSK3 $\beta$ and SFRP1. Biomed Pharmacother 83:508-513. https:// doi.org/10.1016/j.biopha.2016.07.010

Liu B, Zhou W, Jiang H, Xiang Z, Wang L (2019) miR-1303 promotes the proliferation, migration and invasion of prostate cancer cells through regulating the $\mathrm{Wnt} / \beta$-catenin pathway by targeting DKK3. Exp Ther Med 18(6):4747-4757. https://doi.org/10.3892/ etm.2019.8120

Livak KJ, Schmittgen TD (2001) Analysis of relative gene expression data using real-time quantitative PCR and the 2(-Delta Delta C(T)) Method. Methods (san Diego, Calif) 25:402-408

López-Otín C, Blasco MA, Partridge L, Serrano M, Kroemer G (2013) The hallmarks of aging. Cell 153(6):1194-1217. https://doi.org/ 10.1016/j.cell.2013.05.039

Mancini A, Vitucci D, Labruna G, Imperlini E, Randers MB, Schmidt JF, Hagman M, Andersen TR, Russo R, Orrù S, Krustrup P, Salvatore F, Buono P (2017) Effect of lifelong football training on the expression of muscle molecular markers involved in healthy longevity. Eur J Appl Physiol 117:721-730. https://doi.org/10. 1007/s00421-017-3562-8

Mancini A, Vitucci D, Randers MB, Schmidt JF, Hagman M, Andersen TR, Imperlini E, Mandola A, Orrù S, Krustrup P, Buono P (2019) Lifelong football training: effects on autophagy and healthy longevity promotion. Front Physiol. https://doi.org/10.3389/fphys. 2019.00132

Margolis LM, Lessard SJ, Ezzyat Y, Fielding RA, Rivas DA (2017) Circulating MicroRNA are predictive of aging and acute adaptive response to resistance exercise in men. J Gerontol A Biol Sci Med Sci 72:1319-1326

Moresi V, Marroncelli N, Coletti D, Adamo S (2015) Regulation of skeletal muscle development and homeostasis by gene imprinting, histone acetylation and MicroRNA. Biochim Biophys Acta 1849:309-316

Naseeb MA, Volpe SL (2017) Protein and exercise in the prevention of sarcopenia and aging. Nutr Res 40:1-20. https://doi.org/10.1016/j. nutres.2017.01.001

Paulsen G, Lauritzen F, Bayer ML, Kalhovde JM, Ugelstad I, Owe SG et al (2009) Subcellular movement and expression of HSP27, alphaB-crystallin, and HSP70 after two bouts of eccentric exercise in humans. J Appl Physiol 107:570-582. https://doi.org/10.1152/ japplphysiol.00209.2009

Petriz BA, Gomes CPC, Almeida JA, de Oliveira GP, Ribeiro FM, Pereira RW, Franco OL (2017) The effects of acute and chronic exercise on skeletal muscle proteome. Review J Cell Physiol 232(2):257-269. https://doi.org/10.1002/jcp.25477

Qin L, Guo J, Zheng Q, Zhang H (2016) BAG2 structure, function and involvement in disease. Cell Mol Biol Lett 21:18. https://doi.org/ 10.1186/s11658-016-0020-2

Quan W, Lee MS (2013) Role of autophagy in the control of body metabolism. Endocrinol Metab (seoul) 28(1):6-11. https://doi.org/ 10.3803/EnM.2013.28.1.6

Ross CA, Poirier MA (2004) Protein aggregation and neurodegenerative disease. Nat Med 10(Suppl):S10-S17

Schmidt JF, Andersen TR, Andersen LJ, Randers MB, Hornstrup T, Hansen PR, Bangsbo J, Krustrup P (2015) Cardiovascular function is better in veteran football players than age-matched untrained elderly healthy men. Scand J Med Sci Sports 25:61-69

Schmidt M, Schüler SC, Hüttner SS et al (2019) Adult stem cells at work: regenerating skeletal muscle. Cell Mol Life Sci 76:2559-2570

Schönbühler B, Schmitt V, Huesmann H, Kern A, Gamerdinger M, Behl C (2016) BAG2 interferes with CHIP-mediated ubiquitination of HSP72. Int J Mol Sci 18(1):69. https://doi.org/10.3390/ ijms 18010069

Shintani T, Klionsky DJ (2004) Autophagy in health and disease: a double-edged sword. Science 306(5698):990-995. https://doi.org/ $10.1126 /$ science. 1099993

Takayama S, Reed JC (2001) Molecular chaperone targeting and regulation by BAG family proteins. Nat Cell Biol 3(10):E237-E241. https://doi.org/10.1038/ncb1001-e237

Talebian S, Daghagh H, Yousefi B, Özkul Y, Ilkhani K, Seif F, Alivand MR (2020) The role of epigenetics and non-coding RNAs in autophagy: a new perspective for thorough understanding. Mech Ageing Dev 190:111309

Vitucci D, Imperlini E, Arcone R, Alfieri A, Canciello A, Russomando L et al (2018) Serum from differently exercised subjects induces myogenic differentiation in LHCN-M2 human myoblasts. J Sports Sci 36:1630-1639. https://doi.org/10.1080/02640414.2017.14072 32

Walczak M, Martens S (2013) Dissecting the role of the Atg12-Atg5Atg 16 complex during autophagosome formation. Autophagy 9:424-425

Wang HQ, Zhang HY, Hao FJ, Meng X, Guan Y, Du ZX (2008) Induction of BAG2 protein during proteasome inhibitor-induced apoptosis in thyroid carcinoma cells. Br J Pharmacol 155:655-660

Wang C, Wan S, Yang T, Niu D, Zhang A, Yang C, Cai J, Wu J, Song J, Zhang C, Zhang C, Wang J (2016) Increased serum microRNAs are closely associated with the presence of microvascular complications in type 2 diabetes mellitus. Sci Rep 6:20032. https://doi. org/10.1038/srep20032 
Wedel S, Manola M, Cavinato M, Trougakos IP, Jansen-Dürr P (2018) Targeting protein quality control mechanisms by natural products to promote healthy ageing. Molecules 23:E1219

Zhang S, Feng J, Wang L, Guo W, Du Y, Ming L, Zhao G (2014) miR-1303 targets claudin-18 gene to modulate proliferation and invasion of gastric cancer cells. Dig Dis Sci 59(8):1754-1763. https://doi.org/10.1007/s10620-014-3107-5

Zhu CH, Mouly V, Cooper RN, Mamchaoui K, Bigot A, Shay JW, Wright WE (2007) Cellular senescence in human myoblasts is overcome by human telomerase reverse transcriptase and cyclindependent kinase 4: consequences in aging muscle and therapeutic strategies for muscular dystrophies. Aging Cell 6(4):515-523

Publisher's Note Springer Nature remains neutral with regard to jurisdictional claims in published maps and institutional affiliations. 